\title{
A Systematic Review of Controlled Trials of Homeopathy in Bronchial Asthma
}

\author{
Mohammad Qutubuddin $^{\mathrm{a}}$ Shiv Murty Singh ${ }^{\mathrm{b}}$ Chaturbhuja Nayak ${ }^{\mathrm{c}}$ \\ Munmun Koley ${ }^{d}$ Subhranil Saha ${ }^{\mathrm{e}}$ \\ ${ }^{a}$ Department of Homeopathy, District Joint Hospital, Government of Bihar, Darbhanga, India; ${ }^{b}$ Department \\ of Organon of Medicine and Homoeopathic Philosophy, Sri Sai Nath Postgraduate Institute of Homoeopathy, \\ Allahabad, India; ${ }^{C}$ Homoeopathy University Jaipur, Jaipur, India; ${ }^{d}$ Independent Researcher affiliated to Central

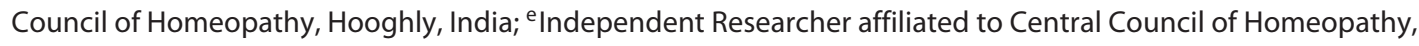 \\ Howrah, India
}

\section{Keywords}

Systematic review $\cdot$ Homeopathy $\cdot$ Bronchial asthma . Controlled trials

\begin{abstract}
Homeopathy is a controversial form of complementary therapy, but is widely practised to treat asthma. The aim of this systematic review is to evaluate the controlled trials of homeopathy in bronchial asthma. Relevant trials published between Jan 1, 1981, and Dec 31, 2016, were considered. Substantive research articles, conference proceedings, and master and doctoral theses were eligible. Methodology was assessed by Jadad's scoring, internal validity by the Cochrane tool, model validity by Mathie's criteria, and quality of individualization by Saha's criteria. Sixteen trials were eligible. The majority were positive, especially those testing complex formulations. Methodological quality was diverse; 8 trials had "high" risk of bias. Model validity and individualization quality were compromised. Due to both qualitative and quantitative inadequacies, proofs supporting individualized homeopathy remained inconclusive. The trials were positive (evidence level A), but inconsistent, and suffered from methodological heterogeneity, "high" to "uncertain" risk of bias, incomplete study reporting, inadequacy of independent replications, and small sample sizes.

(c) 2019 S. Karger AG, Basel
\end{abstract}

\section{Schlüsselwörter}

Systematische Übersichtsarbeit · Homöopathie · Asthma bronchiale $\cdot$ Kontrollierte Studien

\section{Zusammenfassung}

Homöopathie ist eine kontrovers diskutierte Methode der Komplementärmedizin, die in der Asthmabehandlung dennoch häufig eingesetzt wird. Mit der vorliegenden systematischen Übersichtsarbeit sollen die kontrollierten Studien zur Homöopathie bei Asthma bronchiale bewertet werden. Dabei wurden relevante Studien, die zwischen dem 1. Januar 1981 und dem 31. Dezember 2016 veröffentlicht worden waren, berücksichtigt. Stichhaltige wissenschaftliche Artikel, Kongressbände sowie Master- und Doktorarbeiten wurden in die Untersuchung eingeschlossen. Die Bewertung der Methodik erfolgte anhand der JadadSkala sowie durch Beurteilung der internen Validität mittels Cochrane-Tool, der Modellvalidität gemäß den Mathie-Kriterien und der Qualität der Individualisierung entsprechend den Saha-Kriterien. Sechzehn Studien wurden in die Arbeit eingeschlossen. Die meisten kamen zu positiven Ergebnissen, insbesondere jene, die komplexe Formulierungen untersuchten. Hinsichtlich der methodischen Qualität unterschieden sich die Studien, und 8 Studien wiesen ein "hohes" Verzerrungsrisiko auf. Modellvalidität und Qualität der Individualisierung waren eingeschränkt. Aufgrund der qualitativen und quantitativen Unzulänglichkeiten fanden sich keine eindeutigen Hinweise,

\section{KARGER}

(C) 2019 S. Karger AG, Basel 
die die individualisierte Homöopathie stützen. Die Studien fielen positiv (Evidenzklasse A), jedoch inkonsistent, aus und waren durch ihre methodische Heterogenität, ein "hohes" bis "unklares" Verzerrungsrisiko, unvollständige Studienberichte, Unzulänglichkeit der unabhängigen Wiederholungen sowie kleine Stichprobengrößen eingeschränkt.

\section{Introduction}

\section{Rationale}

Homeopathy has remained one of the most widespread and controversial forms of complementary medicine and is used to treat asthma. The prevalence estimates of complementary therapy use for asthma vary widely, from 6 to $70 \%$ [1-3]. However, the clinical evidence remains unconvincing regarding the effectiveness of complementary therapies and homeopathy for asthma [4]. In addition, systematic reviews identified the paucity of high-quality randomized controlled trials in homeopathy [5-13]. There are several distinct forms of homeopathy in practice - "individualized," "clinical," "complex," and "isopathy." In individualized homeopathy, typically a single homeopathic medicine is selected on the basis of the "totality of symptoms" of a patient, including mental, general, and constitutional type and "miasmatic expressions." In clinical homeopathy, one or more homeopathic medicines are administered for standard clinical conditions or conventional diagnoses. In complex homeopathy, several homeopathic medicines are combined in a fixed formulation. Isopathy, also popularly known as "homeopathic immunotherapy" (HIT), is the use of homeopathic dilutions from the causative agent of the disease itself (e.g., organisms or allergens), or from a product of the disease process, to treat the condition, strategically different from individualized homeopathic prescribing in the classic sense. However, a Cochrane systematic review [8] in the previous decade concluded that there was not enough evidence to reliably assess the possible role of homeopathy in asthma because of heterogeneity in the type of homeopathy and study designs; and until stronger evidence existed, no further recommendations could be made about homeopathic treatment. Since publication of this paper, no further systematic review has been undertaken in the concerned subject.

\section{Objectives}

The aim of the present analysis was to systematically review the literature on homeopathic controlled clinical studies of bronchial asthma published between 1980 and 2016 and to evaluate whether homeopathy treatment (alone or as additive to standard therapy) could produce any different effect from control (placebo or standard therapy) in the reported outcomes. Reporting of this systematic review was compliant to the PRISMA statement [14-16].

\section{Materials and Methods}

\section{Protocol and Registration}

The review protocol was adherent to the PRISMA-P guidelines $[17,18]$ and was registered in the PROSPERO database (International Prospective Register of Systematic Reviews, National Institute for Health Research, Centre for Reviews and Dissemination, University of York, UK) prospectively (Reg. No. 42017071609).

\section{Inclusion/Exclusion Criteria}

Controlled trials (randomized, non-randomized, or observational) of any form of homeopathy in patients suffering from persistent and chronic bronchial asthma, published between Jan 1, 1981, and Dec 31, 2016, without any language restriction.

\section{Information Sources}

Substantive research articles (either peer-reviewed or not) as well as conference proceedings and master and doctoral theses were eligible for screening. Book chapters and abstracts were excluded. A list of reprint articles is presented in Appendix I. Articles excluded due to insufficient reporting are listed in Appendix II.

\section{Searches}

Different medical databases including MEDLINE (via PubMed), EMBASE (Elsevier), Cochrane Central Register of Controlled Trials (CENTRAL) (Wiley interface), CORE-Hom (Carl and Veronica Carstens-Stiftung), ChiroACCESS (MANTIS interface), LILACS (Biblioteca virtual em salud interface), and Google Scholar were used for the literature search. Various search terms were used for different databases, for example:

MEDLINE: homeopath* OR homoeopath* AND "randomized controlled trial" OR "controlled clinical trial" OR "randomized" OR "placebo"

EMBASE: homeopath\$ OR homoeopath\$

CENTRAL: homeopathy (MeSH)

CORE-Hom: Specifying the field "Respiratory tract disorder" (138 hits)

ChiroACCESS: homeopath* OR homoeopath*

LILACS: homeopath\$ AND random\$

Besides, hand search was made into different journals, magazines, meeting abstracts, and bibliographic sections of reviews, meta-analyses, and original trial papers. The most recent search was carried out in August 2017.

\section{Study Selection}

Selection included randomized and non-randomized controlled trials and controlled observational studies of any form of homeopathy in bronchial asthma.

\section{Data Collection Process}

Data extraction was performed utilizing standardized Microsoft Excel files. Two reviewers (M.K. and S.S.) extracted the data and double-checked the information independently. Discrepancies, if any, were resolved by consulting with another independent reviewer (C.N.). The classification of the therapeutic approaches was made according to a grade of evidence in six levels, which had been developed by Natural Standard, an international research collaboration that aggregates and synthesizes data on complementary and alternative therapies (http://www.naturalstandard.com/ index.asp). A summary of these criteria is reported in online supplementary Table 1 (for all online suppl. material, see www.karger. com/doi/10.1159/000494621). 


\section{Data Items}

The following data was extracted from the included studies:

1 Publication type (substantive research article peer-reviewed; substantive research article non-peer-reviewed; minor research article peer-reviewed; thesis; minor research article nonpeer-reviewed; master thesis; doctoral thesis; conference proceedings); the levels of evidence of the studies and publications are graded as per criteria mentioned in online supplementary Tables 2 and 3 .

2 Study aim and target population

3 Inclusion and exclusion criteria

4 Study design (randomized controlled trials, controlled cohort study, case-control study)

5 Intervention details (potency; type of homeopathy (individualized/classical; clinical; complex; isopathy; preventive)

6 Control details: placebo or conventional treatment as control; homeopathy as additive or not

7 Number of patients that have participated, and that have been evaluated in each group; attrition rate; intention-to-treat or per-protocol analysis

8 Statistical reporting: measures of central tendency and dispersion for continuous data, number of favourable events for dichotomous data, etc. As we expected considerable variety in outcomes - both primary and secondary, those were planned to be reported in all data formats (e.g., dichotomous, continuous).

9 Funding and declared conflicts of interest.

\section{Risk of Bias in Individual Studies}

Two reviewers (M.K. and S.S.) independently assessed the methodological aspects of the included studies. Disagreements on data extraction were resolved by discussion and participation of another reviewer (C.N.). If information was missing, the study authors were contacted by e-mail.

Firstly, the methodological quality was assessed by the Jadad scoring system [19] in the following domains:

1 Randomization

2 Blinding

3 Description of withdrawals and drop-outs

The internal validity of the trials was evaluated by the Cochrane Collaboration tool for assessing the risk of bias in randomized trials [20] for the seven following domains:

1 Random sequence generation

2 Allocation concealment

3 Blinding of participants and personnel

4 Blinding of outcome assessors

5 Incomplete outcome data, i.e., whether all the randomized patients are accounted for in the analysis

6 Selective reporting

7 Anything else

The internal validity of the observational studies was assessed by the Cochrane risk of bias assessment tool for non-randomized studies of interventions $[21,22]$ for the seven following bias domains:

1 Confounding

2 Selection of participants into the study

3 Measurement of interventions

4 Departures from intended interventions

5 Missing data

6 Measurement of outcomes

7 Selection of reported results.

By the standard Cochrane approach, each trial is designated as follows:

(a) low risk of bias for all key domains;

(b) uncertain risk of bias for one or more key domains; and (c) high risk of bias for one or more key domains.

The novel method of nomenclature was adopted based on the Cochrane approach for rating risk-of-bias characteristics across all domains per trial as proposed by Mathie et al. [23] (2014) as follows:

$A=$ Low risk of bias in all seven domains

$\mathrm{Bx}=$ Uncertain risk of bias in $\mathrm{x}$ domains; low risk of bias in all other domains

Cy.x $=$ High risk of bias in y domains; uncertain risk of bias in $\mathrm{x}$ domains; low risk of bias in all other domains.

The homeopathic model validity was evaluated by the six judgemental domains proposed by Mathie et al. [24] (2015):

1 Rationale for the choice of the particular homeopathic intervention

2 Homeopathic principles reflected in the intervention

3 Extent of homeopathic practitioner input

4 Nature of the main outcome measure

5 Capability of the main outcome measure to detect change

6 Length of the follow-up to the endpoint of the study.

The quality of homeopathic individualization was evaluated by the six judgemental criteria proposed by Saha et al. [25] (2014):

1 Single medicine prescription when required on each occasion

2 Medicine individualization

3 Proper description of approach to medicine individualization

4 Dose individualization

5 Proper description of approach to dose individualization

6 Subsequent prescriptions as per Kent's observations and/or Hering's law.

\section{Summary Measures}

Keeping in mind the heterogeneity in homeopathy trials in terms of intervention, study designs, and outcome reporting, as identified in the earlier meta-analyses as well, it seemed inappropriate to draw any summary measure (e.g., odds ratio, risk ratio, etc.) and to combine them into quantitative meta-analytic models comparing treatment effects of homeopathic medicines with those of placebo or standard therapies.

Synthesis of Results

A narrative synthesis of the findings from the included studies, structured around outcome and intervention/comparator was provided.

\section{Risk of Bias across Studies and Additional Analyses}

None planned.

\section{Results}

\section{Study Selection}

A total of 1,218 records were identified by electronic and manual searches between 1981 and 2016 of which 55 records were screened further. Among these, 27 were excluded and 28 records were considered further. Of these, there were 16 controlled trials and 12 uncontrolled observational studies (see study flow diagram; Fig. 1).

\section{Study Characteristics}

Sixteen controlled trials [26-41] (online suppl. Table 4) and 12 uncontrolled observational studies [42-53] (online suppl. Table 5) of homeopathy in bronchial asth- 


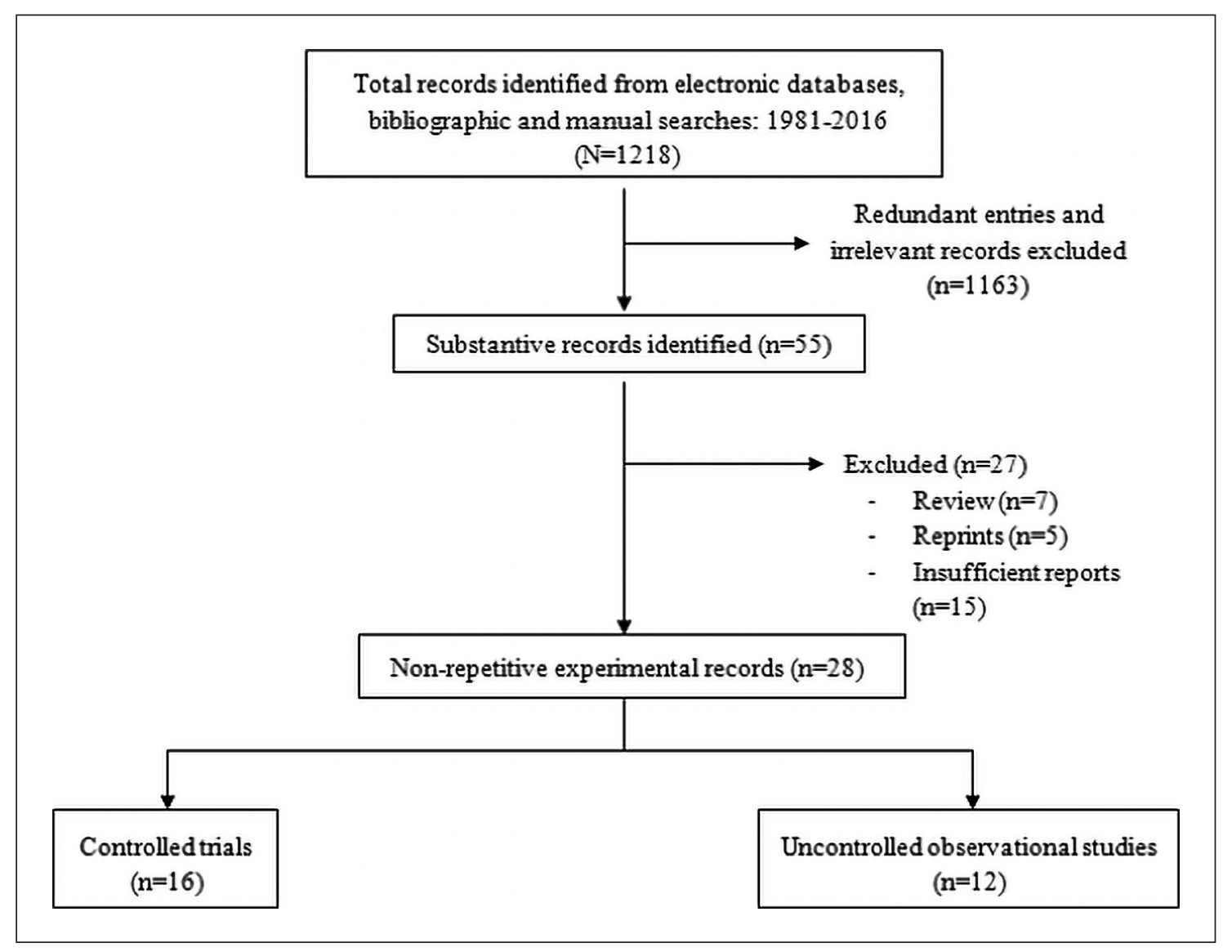

Fig. 1. Study flow diagram.

ma were identified. Thus, the level of evidence was graded as A (strong scientific evidence, i.e., statistically significant evidence of benefit from more than 2 properly conducted randomized trials; online suppl. Table 1). For each controlled trial, the following characteristics - study and publication type, aim, population and setting, exclusion and inclusion criteria, design, intervention, control, number of patients, and attrition and analysis (per proto$\mathrm{col} / \mathrm{PP}$ or intention to treat/ITT), key results, study funding, and declared conflict of interest - were extracted and are arranged with citations in online supplementary Table 4 . Among the 16 controlled trials, 6 were of complex homeopathy, 5 of individualized homeopathy, 3 of HIT, and 2 of clinical homeopathy. Data for the observational uncontrolled studies was also extracted and is presented in online supplementary Table 5. Among these 12 uncontrolled studies, individualized, clinical, and HIT were tested in 8,3 , and 1 study, respectively.

\section{Risk of Bias within Studies}

Methodological quality, as analysed by Jadad scoring, was judged to be diverse, ranging from 1 to 5 (online suppl. Table 6). Risk of bias in each controlled trial, as evaluated by using seven domains of Cochrane Collaboration tool (detailed in Materials and Methods) is elaborated in online supplementary Table 7. Eight trials had "high" risk of bias, while 8 had "uncertain" risk of bias. Model validity was also compromised - only 3 had "acceptable" rating, two were "uncertain," and the remaining 11 were "inadequate" (online suppl. Table 8). Similar evaluation was also performed using the individualization scoring method - the trials having model validity designated as "acceptable" and "uncertain" got a score of 2 or 3 out of 6 , respectively; the rest of the trials got a score of 0 to 1 (online suppl. Table 9). Similarly, risk of bias, model validity, and quality of individualization were also assessed for the uncontrolled observational studies (online suppl. Tables 10-12). All the studies had "high" risk of bias (online suppl. Table 10), "inadequate" model validity (except 2 studies; online suppl. Table 11) with variable scores of 1-4 on individualization (online suppl. Table 12).

\section{Discussion}

\section{Summary of Evidence}

Sixteen controlled trials of homeopathy in bronchial asthma were identified. The trials were heterogeneous in 
terms of type of homeopathy used, methodological qualities, risk of bias, model validity, and quality of individualization. Most of them were double blind, randomized, parallel arm, and placebo controlled, and homeopathy was mostly used as additive to standard care. The majority of the studies were positive, and the level of evidence could be graded as A (strong scientific evidence). All the controlled trials testing complex homeopathic products were funded and yielded positive results, thus raising additional concern regarding whether these studies were free from vested interest or not. Proof in support of individualized homeopathy remained equivocal and inconclusive. Evidence in support of HIT or clinical homeopathy remained sparse. Besides, due to wide variability and incompleteness in study reporting, "high" to "uncertain" risk of bias, inadequacy of independent replications, and small sample sizes, quantitative pooling of the effect sizes into a meta-analytic model seemed inappropriate and improbable. Considerable heterogeneity was also identified in terms of the selected outcome measures - ranging from objective to different subjective outcomes. Objective outcomes included spirometry readings, granulocyte functions, etc., whereas subjective measures included symptom intensity measuring visual analogue scales, frequency of asthma attacks and medication use, number of withdrawals and drop-outs, clinical assessments and scorings, quality of life questionnaire, patient-rated relief, etc. The target sample included both children and adults. Intervention was also varied in terms of individualized, clinical, complex, immunotherapy, and often as adjunctive to usual care. Positive responses were elicited predominantly on symptom severity subjective outcomes, frequency of asthmatic attacks and use of standard medications, and immunological markers, whereas responses obtained on lung functions were equivocal and negative on quality of life outcomes. Outcomes from controlled trials were always favourable for complex homeopathy, but ambivalent in cases of other forms of homeopathy - classic or individualized, immunotherapy or clinical. Contrarily, evidence from non-controlled trials was in support of both individualized and clinical homeopathy, against immunotherapy, but none existed of complex homeopathy. We recommend both placebocontrolled (in the mutual context of usual care) and pragmatic models testing the efficacy and effectiveness of homeopathy, respectively, by using both subjective and objective measures and allowing practitioners to prescribe freely in their usual way. It is important to test homeopathy in the form in which it is commonly practised rather than in a form specially curtailed for clinical trials. The trials should keep provision for input of more than one experienced homeopath in order to counter any negative result attributed to lack of competence of a single therapist.

\section{Limitations}

All the relevant papers were captured by electronic and manual searches into all available databases and bibliographies; nevertheless, retrieval may be incomplete. At this stage, any meta-analysis of the existing results is not possible; rather, further adequately powered trials and replications are recommended.

\section{Conclusion}

Overall, the findings of this review seem to be promising enough and qualitatively suggest a definite role of homeopathy beyond placebo in the treatment of bronchial asthma; however, they are not adequately supported by level A evidence. Though few trials were rated as $1 \mathrm{a}$ or $1 \mathrm{~b}$, they still suffered from many important caveats including inadequate power and sample size and less robust designs in terms of randomization, blinding, and choice of outcome measures. Independent replications and further evaluation in appropriate and rigorous designs are warranted.

\section{Acknowledgements}

The authors are grateful to Prof. Dr. Ramjee Singh, MD Hom, President, Central Council of Homoeopathy; Dr. Tarkeshwar Jain, MD Hom, Registrar, Homoeopathy University, Jaipur; and Dr. Sayed Tanvir Hussain, MD Hom, Director, Dr. Tanvir's Homoeopathic Cancer Care Centre, Chandigarh, for their technical input and contribution to the study.

\section{Statement of Ethics}

The authors have no ethical conflicts to disclose.

\section{Disclosure Statement}

The authors have no conflicts of interest to declare. The review was carried out as part of $\mathrm{PhD}$ thesis of the corresponding author.

\section{Funding Sources}

No funding was received for the project. The institution had no role to play in analysis of the study results and publication of the paper.

\section{Author Contributions}

M.Q. and S.M.S. were involved in the concept, design, literature search, data extraction and interpretation, and preparation of the article. C.N., M.K., and S.S. participated in data extraction and interpretation, and preparation of the article. All the authors edited, reviewed, and approved the final article. 


\section{Appendix I}

List of Reprint Articles

1 Matusiewicz R. The effect of a homeopathic preparation on the clinical condition of patients with corticosteroid-dependent bronchial asthma [Die Wirkung einer homöopathischen Präparation auf den klinischen Zustand von Patienten mit kortikosteroidabhängigem Bronchial asthma]. Biomed Ther. 1997;15:70-4.

2 Matusiewicz R, Rotkiewicz-Piorun A. Behandlung schwerer Formen von kortikoidabhängigem Bronchialasthma mit Immunsuppressiva und Antihomotoxischen Mitteln. Biol Med. 1997;26:67-72.

3 Matusiewicz R. The homeopathic treatment of corticosteroid dependent asthma: a double blind, placebo-controlled study [Die homöopathische Behandlung von Kortikosteroid abhängigem Asthma: eine doppelblinde, Placebo-kontrollierte Studie]. Biomed Ther. 1997;4:117-22.

4 Lewith GT. A double-blind, randomised, controlled clinical trial of ultramolecular potencies of house dust mite in asthmatic patients. Forsch Komplementmed. 2000;7:46.

5 Reilly DT, Taylor MA, Campbell J, Beattie N, McSharry C, Aitchison T, Carter R, Stevenson R. Is homeopathy a placebo response? A controlled trial of homoeopathic immunotherapy (HIT) in atopic asthma. Abstracts of the International Congress on Ultra-Low Doses - Biological and Clinical Applications on Ultra-Low Doses; 1990 Sep 20-22; Bordeaux, France. p. 51-2.

\section{Appendix II}

\section{Articles Excluded due to Insufficient Reporting}

1 Blackie MG. Asthma. Br Homeopath J. 1932;22:179.

2 Zotou P. Statistical study of the results of treatment of childhood asthma by homoeopathic remedies. Proceedings of the 43rd LMHI Congress; 1988; Athens, Greece; p. 284-305.
3 Diamantidis S, Polychronopulu A, Kivelou P, Papakonstadinu G. The homoeopathic treatment of chronic bronchial asthma. Homoeopath Int. 1989;3:7-9.

4 Hari S, Savita K. A study of 413 cases of bronchial asthma. Quinquina Homoeopathic Quarterly. 1992-93;113:13-9.

5 Herring P. Curing asthma naturally: a variety of asthma cases. Similimum. 1999;12:51-60.

6 Brunini DCR. Quality of life and homeopathic approach in asthmatic children [Qualidade de vida e abordagem homeopatica em crianc as asmaticas]. Infanto. 2002;10:18-21.

7 Frenkel M, Hermoni D. Effects of homeopathic intervention on medication consumption in atopic and allergic disorders. Altern Ther Health Med. 2002;8:76-9.

8 Dantas F. Homeopathy in childhood asthma. Thorax. 2003;58: 826.

9 Fisher P, Chatfield K, Mathie R. Homeopathy in childhood asthma. Thorax. 2003;58:827.

10 Witt C, Keil T, Selim D, Roll S, Vance W, Wegscheider K, Willich SN. Outcome and costs of homoeopathic and conventional treatment strategies: a comparative cohort study in patients with chronic disorders. Complement Ther Med. 2005;13:7986.

11 Colin P. Homeopathy and respiratory allergies: a series of 147 cases. Homeopathy. 2006;95:68-72.

12 Mohan GR. Efficacy of Homeopathy in Childhood Asthmas. Homeopath Links. 2007;20:104-7.

13 Ketata M, Villano G, Ben Salah-Mezghanni S, Pellegrini A, Hayouni A, Mtiraoui A. Homeopathic therapeutics of allergic asthma (about six cases) [Asthme allergique et therapeutique homeopathique (a propos de six cas)]. Proceedings of the 63rd LMHI Congress; 2008; Ostend, Belgium. p. 1-12.

14 Macri F. Medical Audit on paediatric patients with allergic disorders. Proceedings of the 63rd LMHI Congress; 2008; Ostend, Belgium. p. 1-4.

15 Topcu A, Dahl R, Nielsen LP, Eriksen L, Langgaard A. Effect of reflexology, homeopathy, and traditional medical treatment in asthma: A randomized controlled, parallel-group trial. Poster presented at ICCMR 2010; 2010 May; Tromso, Norway.

\section{References}

1 Partridge MR, Dockrell M, Smith NM. The use of complementary medicines by those with asthma. Respir Med. 2003 Apr;97(4): 436-8.

2 Jørgensen V, Launsø L. Patients' choice of asthma and allergy treatments. J Altern Complement Med. 2005 Jun;11(3):529-34.

3 Schäfer T. Epidemiology of complementary alternative medicine for asthma and allergy in Europe and Germany. Ann Allergy Asthma Immunol. 2004 Aug;93(2 Suppl 1):S5-10.

4 Mokhtar N, Chan SC. Use of complementary medicine amongst asthmatic patients in primary care. Med J Malaysia. 2006 Mar;61(1): 125-7.

5 Lewith GT, Watkins AD. Unconventional therapies in asthma: an overview. Allergy. 1996 Nov;51(11):761-9.

6 Poitevin B. Review of experimental studies in allergy: clinical studies. Br Homeopath J. 1998;87(02):89-99.

7 Linde K, Jobst KA. Homeopathy for chronic asthma. Cochrane Database Syst Rev. 2000;(2):CD000353.
8 McCarney RW, Linde K, Lasserson TJ. Homeopathy for chronic asthma. Cochrane Database Syst Rev. 2004;(1):CD000353.

9 Bellavite P, Ortolani R, Pontarollo F, Piasere $\mathrm{V}$, Benato G, Conforti A. Immunology and homeopathy. 4. Clinical studies - Part 2. Evid Based Complement Alternat Med. 2006;3(4): 397-409.

10 Bellavite P, Chirumbolo S, Magnani P, Ortolani R, Conforti A. Effectiveness of homeopathy in immunology and inflammation disorders. A literature overview of clinical studies. Homoeopathic Heritage International. 2008; 33(2)35-7.

11 McCarney RW, Lasserson TJ, Linde K, Brinkhaus B. An overview of two Cochrane systematic reviews of complementary treatments for chronic asthma: acupuncture and homeopathy. Respir Med. 2004 Aug;98(8): 687-96.
12 Ullman D, Frass M. A review of homeopathic research in the treatment of respiratory allergies. Altern Med Rev. 2010 Apr;15(1):48-58.

13 Sharma B, Narula RH, Manchanda RK. Homoeopathy for the management of asthma A review of Council's Clinical Research. Indian J Res Homoeopathy. 2015;9(2):69-78.

14 Moher D, Liberati A, Tetzlaff J, Altman DG; PRISMA Group. Preferred reporting items for systematic reviews and meta-analyses: the PRISMA statement. BMJ. 2009 Jul;339:b2535.

15 Liberati A, Altman DG, Tetzlaff J, Mulrow C, Gøtzsche PC, Ioannidis JP, et al. The PRISMA statement for reporting systematic reviews and meta-analyses of studies that evaluate health care interventions: explanation and elaboration. PLoS Med. 2009 Jul; 6(7):e1000100.

16 Beller EM, Glasziou PP, Altman DG, Hopewell S, Bastian H, Chalmers I, et al.; PRISMA for Abstracts Group. PRISMA for Abstracts: reporting systematic reviews in journal and conference abstracts. PLoS Med. 2013;10(4):e1001419. 
17 Shamseer L, Moher D, Clarke M, Ghersi D, Liberati A, Petticrew M, et al.; PRISMA-P Group. Preferred reporting items for systematic review and meta-analysis protocols (PRISMA-P) 2015: elaboration and explanation. BMJ. 2015 Jan;350:g7647.

18 Moher D, Shamseer L, Clarke M, Ghersi D, Liberati A, Petticrew M, et al.; PRISMA-P Group. Preferred reporting items for systematic review and meta-analysis protocols (PRISMA-P) 2015 statement. Syst Rev. 2015 Jan;4(1): 1 .

19 Jadad AR, Moore RA, Carroll D, Jenkinson C, Reynolds DJ, Gavaghan DJ, et al. Assessing the quality of reports of randomized clinical trials: is blinding necessary? Control Clin Trials. 1996 Feb;17(1):1-12.

20 Higgins JP, Altman DG, Gøtzsche PC, Jüni P, Moher D, Oxman AD, et al.; Cochrane Bias Methods Group; Cochrane Statistical Methods Group. The Cochrane Collaboration's tool for assessing risk of bias in randomised trials. BMJ. 2011 Oct;343:d5928.

21 Sterne J, Higgins J, Reeves B, editors. A Cochrane risk of bias assessment tool: for nonrandomized studies of interventions (ACROBAT-NRSI). Version 1.0.0 [cited 2014 Sep 24]. Available from: http://www.riskofbias. info.

22 Sterne JA, Hernán MA, Reeves BC, Savović J, Berkman ND, Viswanathan $\mathrm{M}$, et al. ROBINS-I: a tool for assessing risk of bias in nonrandomised studies of interventions. BMJ. 2016 Oct;355:i4919.

23 Mathie RT, Lloyd SM, Legg LA, Clausen J, Moss S, Davidson JR, et al. Randomised placebo-controlled trials of individualised homeopathic treatment: systematic review and meta-analysis. Syst Rev. 2014 Dec;3(1):142.

24 Mathie RT, Van Wassenhoven M, Jacobs J, Oberbaum M, Roniger H, Frye J, et al. Model validity of randomised placebo-controlled trials of individualised homeopathic treatment. Homeopathy. 2015 Jul;104(3):164-9.

25 Saha S, Koley M, Ganguly S, Rath P, Roy Chowdhury P, Hossain SI. Developing the criteria for evaluating quality of individualization in homeopathic clinical trial reporting: a preliminary study. J Integr Med. 2014 Jan;12(1):13-9.

26 Campbell JH, Taylor MA, Beattie N, McSharry $\mathrm{C}$, Aitchison $\mathrm{T}$, Carter $\mathrm{R}$, et al. Is homeopathy a placebo response? A controlled trial of homeopathic immunotherapy in atopic asthma. Am Rev Respir Dis. 1990;141:A24.

27 Boucinhas JC, de Medeiros Boucinhas ID Prevention of asthma exacerbations in children with histamine 5CH [Prophylaxie des crises d'asthme bronchique chez l'enfant par l'usagde de Poumon histamine $5 \mathrm{CH}]$. Homeopath Fr. 1990;78:35-9.
28 Reilly D, Taylor MA, Beattie NG, Campbell $\mathrm{JH}, \mathrm{McSharry} \mathrm{C}$, Aitchison TC, et al. Is evidence for homoeopathy reproducible? Lancet. 1994 Dec;344(8937):1601-6.

29 Freitas LA, Goldenstein E, Sanna OM. The indirect doctor patient relationship and the homeopathic treatment of asthma in children. Rev Homeopatia. 1995;60:26-31.

30 Matusiewicz R. Efficacy of Engystol N in bronchial asthma under corticoid-dependent therapy [Wirksamkeit von Engystol $\mathrm{N}$ bei Bronchialasthma unter kortikoidabhängiger Therapie]. Biol Med. 1995;24:242-6.

31 Matusiewicz R. Traumeel S in the treatment of corticosteroid-dependent bronchial asthma [Traumeel S in der Behandlung von kortikoidabhängigem Bronchialasthma]. Biol Med. 1996;25:107-12.

32 Lara-Marquez ML, Pocino M, Rodriguez F, Carvallo GE, Ortega CF, Rodriguez C. Homeopathic treatment for atopic asthma lung function and immunological outcomes in a randomized clinical trial in Venezuela. Proceedings of the 52nd LMHI Congress; 1997; Seattle, USA. p. 73.

33 Jansen G, Koster T, Haidvogl M, Heger M. The homeopathic treatment of asthma. A randomized clinical trial. Proceedings of the 52nd LMHI Congress; 1997; Seattle, USA. p. $74-80$.

34 Riveron-Garrote M, Fernandez-Argulles R, Moron-Rodriguez F, Campistrou-Labaut JL. Randomized controlled clinical trial of homeopathic treatment of bronchial asthma [Ensayo clinic controlado aleatorizado del tratamiento homeopàtico del asma bronquial]. Bol Mexicano Homeopatia. 1998;31:5461.

35 Matusiewicz R, Wasniewski J, Sterna-Bazanska A, Hulsberg M. Treatment of chronic asthma with a homeopathic complex [Behandlung des chronischen Asthma bronchiale mit einem homöopathischen Komplexmittel]. Erfahrungsheilkunde. 1999;6:367-74.

36 Lewith GT, Watkins AD, Hyland ME, Shaw S, Broomfield JA, Dolan G, et al. Use of ultramolecular potencies of allergen to treat asthmatic people allergic to house dust mite: double blind randomised controlled clinical trial. BMJ. 2002 Mar;324(7336):520.

37 Suri JC, Pusch D, Orth-Wagner S. Effectiveness of a natural immunomodulator in the treatment of bronchial asthma [Wirksamkeit eines natürlichen Immunmodulators in der Behandlung von Asthma bronchiale]. Ärztezeitschrift Naturheilverfahren 2002;43(9): 594-600.

38 White A, Slade P, Hunt C, Hart A, Ernst E. Individualised homeopathy as an adjunct in the treatment of childhood asthma: a randomised placebo controlled trial. Thorax. 2003 Apr;58(4):317-21.
39 Delzoppo G. Asthmatic bronchitis therapy in pediatric age: homeopathic protocol vs. corresponding allopathic protocol of reference [Terapie della bronchite asmatica in etá pediatrica: protocollo omeopatico vs. protocollo allopatico corrispondente die riferimento]. Med Biol (Milano). 2004;1:3-7.

40 Mayra RG, Marisol AR, Rabassa PJ, Natalia MS, Christian LL. Determination of the effectiveness of Biomodulina $\mathrm{T}$ in asthmatic children with recurring respiratory infections. Gac Homeop Caracas. 2005;13(1):21-26.

41 Thompson EA, Shaw A, Nichol J, Hollinghurst S, Henderson AJ, Thompson T, et al. The feasibility of a pragmatic randomised controlled trial to compare usual care with usual care plus individualised homeopathy, in children requiring secondary care for asthma. Homeopathy. 2011 Jul;100(3):122-30.

42 Anil RB, Amar K, Kothari SR. Role of Arsenic iodatum during acute attack of asthma. CCRH Quarterly Bulletin. 1982;4:21-2.

43 Anil RB, Chillar YS, Amar KB, Vinod VG. Comparative study of the indications of Arsenic alb./iod., Kali carb., Natrum sulph., and their usefulness in bronchial asthma. CCRH Quarterly Bulletin. 1988;10:16-9.

44 Sachdeva OP, Chillar YS, Ger DD, Suri N, Saxena V. Role of Arsenic album in bronchial asthma. CCRH Quarterly Bulletin. 1988;10: 28.

45 Mosquera PM. Bronchial asthma in childhood: management by means of homeopathia. Proc. 2nd OMHI Congess, Mexico, 156166, 1990.

46 Castellsagu AP. Evolution of 26 cases of bronchial asthma with homoeopathic treatment. Brit Hom J. 1992;81:168-72.

47 Hari S, Savita K. Study of 413 cases of bronchial asthma treated with homoeopathic system of medicine. CCRH Quarterly Bulletin. 1992;13:5-11.

48 Eizayaga FX, Eizayaga J, Eizayaga J. Homoeopathic treatment of bronchial asthma. $\mathrm{Br} \mathrm{Ho-}$ meopath J. 1996;85:28-33.

49 Sharma SR. Wheezing syndrome. CCRH Quarterly Bulletin. 1999;21:6-8.

50 Li AM, Bush A, Wilson NM. Homeopathy in childhood asthma. Thorax. 2003 Sep;58(9): 826-8.

51 Vichitra AK, Sharma SR, Bindu S, Raju K, Indira B, Thomas EC, et al. Bronchial asthma. Clinical Research Series, Series I. 2008. p. 2740.

52 Pinto S, Rao AV, Rao A. Erythrocyte and plasma antioxidants in bronchial asthma before and after homeopathic treatment. J Homeopath Ayurv Med. 2012;1(1):1-7.

53 Shafei HF, AbdelDayem SM, Mohamed NH. Individualized homeopathy in a group of Egyptian asthmatic children. Homeopathy. 2012 Oct;101(4):224-30. 